\title{
Study on the Process of Industrial Design and Styling Design of Mobile Phone for the Elder in New Product Development
}

\author{
Liying WU \\ City Construction College of civil engineering \\ Jiujiang University \\ Jiujiang ,332000,China
}

\begin{abstract}
In order to make the mobile phone close to aesthetic orientation of older users, user more easy operate and control mobile phone interface, the paper takes the theory of usability engineering as an important factor in the research, the core of the theory is "take the customer as the center", it emphasizes on product development should focus on the target user perspective in the process, user actively participate in the initial design stage, in order to get user feedback and iteratively improved design. Applying theory make product design process has a clear direction, which is the design stage to the final completion close to the user's needs.
\end{abstract}

Keywords: The old man's cellular phone; The humanized design; Value Analysis; Factors of mentality;

\section{INTRODUCTION}

When new mobile phone have more and more fashionable styles and the function is more and more advanced in the market, many elderly people were unable to find a suitable for your mobile phone and distress. On the one hand, the mobile phone have relatively high cost now. Even elder people with good economic capacity will stick to the thrifty life style, this is their inherent characteristics, and it is very difficult to change. So they are willing to try new things and pay a high price, not willing to buy higher priced mobile phone. Second, the mobile phone is often complicated operation, the elderly cannot accept. The current mobile phone operation is too complex, not buy operation simple, functional and practical, suitable for the elderly to use "fool" type mobile phone. The elderly accept ability is poor, this is a fact. So face a series of functions, they will have a feeling of rejection. Because too many functions for them, is a burden, they do not have the patience to slowly learn hard to understand things, this will cause a lot of old people are not willing to use mobile phone. Third, the market basically is not suitable for old people to use mobile phone. A simple function of the mobile phone is often out of date, the screen is very small, and the key is very small. The lowend mobile phone with few new mobile phone. Larger screen are multimedia mobile phone, the function is too much. The author in the market survey, pay attention to this problem obviously. But in the new products this year, not suitable for old people to use. The elderly have the pursuit of innovative psychological, they are reluctant to use backward products, they also have their own requirements of the mobile phone market, but no attention to this special group, and their demands are not met.

Therefore, in the product design, the development of mobile phone for the elderly is far from enough attention, it still belongs to the blank design and development of a forgotten corner.

\section{THE BASIC METHOD OF MOBILE PHONE IN INDUSTRIAL DESIGN}

\section{A. Design elements}

Industrial design is an interdisciplinary new disciplines, must adopt the design method of multi discipline cross, in order to achieve the best state of the various elements of the solution, namely the design of an ideal. Factors directly affect the industrial design including human, technical conditions and environmental aspects, as shown in figure 1.

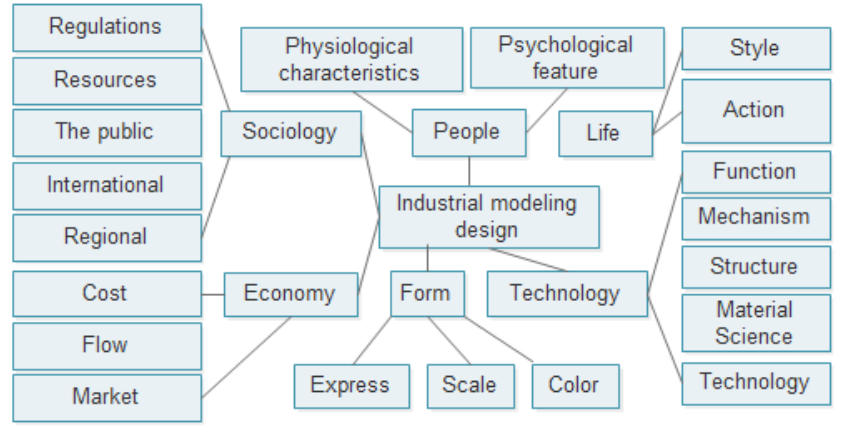

Fig.1 The elements of mobile phone in industrial design

\section{B. The design procedure}

Modern industrial design is the purpose and planned order to expand, the entire design process is sometimes crossed each other. Circulation is to continue to test whether each step in accordance with the design requirements. For a designer, is in the premise of clear design purposes, the first comprehensive research and design of various design factors related, and then consciously trying various combinations of possible; followed by inoculation process, and then put forward the aim of design solutions can be achieved; finally through mechanism design of science to open up the market products. The specific procedures are as follows: 


\section{1) Survey}

According to the age characteristics to choose the target user, primary population was 60 years of age or older, by selecting the part of questionnaire survey a total of 50 sample, choose 20 typical user testing. In a typical user selection mainly ordinary user group for consideration, comprehensive consideration of the occupation, the area, level of education, living condition etc.. Through the method of user operation process in questionnaire survey and in-depth interview were obtained, we can get the typical user demand point.

- begun preliminary investigation, data collection and research work

- It was found that the main problems need to be solved:

- started competitive analysis, strategies

- Study to use technology, development platform and media

Results: the project plans to develop

2) Creativity

Hand-painted can flexible record the inspiration in the draft program design, conducive to the self-scrutiny and mutual exchange. When a large number of end stage for various sketches of divergent thinking, come back to look at these sketches, for useful place can color or icon as a marker, one by one examination, will be useful to sketch rearranged, and with new sketches to integrate the useful part of the mark, so as to form several more complete sketch, this is the process of creative thinking from the divergence to convergence, to the rational integration from perceptual creative. The following is by many designers through the relevant information collection and market survey, divergent thinking design common master competition situation, market situation of existing similar products sales, consumer use and to the new function of the potential demand for the situation, as shown in Figure 2 is the 3 sketch plan after the integration.

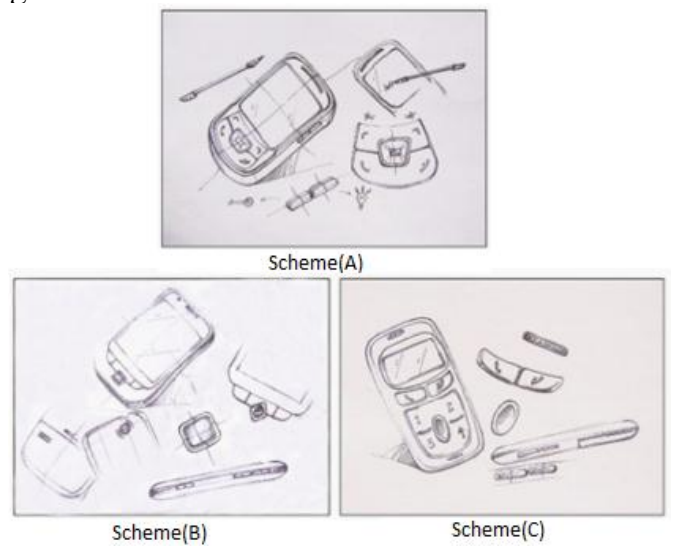

Fig.2 The sketch scheme

- put forward the concept, the creativity and ideas, work environment, the survey efficiency and use interface, so as to further improve the creative

- making concrete engineering design drawings and plastic model

- Selected materials, determine the production process and technical structure

Results: the concept of the two step is forming
3) Sketch scheme evaluation

When the product design draft is basically complete, will begin the appearance molding of the products, color, material is reasonable meet the user identify further needs. According to the usability engineering users participate in the guide, then invited users to participate in together not only to save development time to the design, but also can directly obtain the help user to product design views. Therefore, the design of multiple solutions can have good presentation to the user test, according to test results, we screening to the later scheme.

Evaluation of mobile phone design the elderly first can be carried out by experts experience evaluation, basic principles under the guidance of availability, without the obvious usability problems of the draft, the selection can be further design draft. (See Table 1)

Table.1 Usability criteria evaluate sketch plan

\begin{tabular}{c|c|c|c|c|c|c}
\hline Scheme & Concise & Language & $\begin{array}{l}\text { Reduce the } \\
\text { user's memory } \\
\text { load }\end{array}$ & Use friendly & Error rate & Summary \\
\hline A & B & & & & 9 \\
\hline B & C & & & & & 10 \\
\hline D & & & & & \\
\hline
\end{tabular}

4) The draft program refinement

Analysis of the target user preferences, puts forward some product color scheme through the investigation, find specific answers from. From table 2 shows that black mobile phone is popular in different age of the user in a larger proportion, followed by dark brown.

Table. 2 Mobile phone color investigation

\begin{tabular}{c|c|c|c|c}
\hline $\begin{array}{c}\text { Mobile phone } \\
\text { color (\%) }\end{array}$ & Overall & $60-70$ age & $\begin{array}{c}70-80 \\
\text { age }\end{array}$ & $>80$ old \\
\cline { 2 - 5 } & 248 & 105 & 95 & 48 \\
\hline Black & 51.2 & 42.9 & 44.2 & 66.7 \\
\hline Dark brown & 33.1 & 32.4 & 44.2 & 22.9 \\
\hline Silver & 9 & 12.4 & 6.3 & 8.3 \\
\hline White & 3.3 & 7.7 & 0 & 2.1 \\
\hline Miscellaneous & 3.4 & 3.9 & 6.3 & 0
\end{tabular}

In order to determine material the use of mobile phone products, also put forward some material utilization scheme, let users sampled for scheme selection, grasp the user's aesthetic and preferences from. Table 3 the test results show that the mobile phone, engineering plastic material more interesting by elderly people.

Table. 3 Mobile phone materials investigation

\begin{tabular}{c|c|c|c|c}
\hline \multirow{2}{*}{ Materials (\%) } & Overall & $60-70 a g e$ & $70-80$ age & $>80$ age \\
\cline { 2 - 5 } & 248 & 105 & 95 & 48 \\
\hline Engineering plastics & 37.7 & 23.8 & 41.1 & 54.2 \\
\hline Matte texture & 33.3 & 39 & 40 & 20.8 \\
\hline Brushed metal & 14.3 & 20 & 6.3 & 16.7 \\
\hline Miscellaneous & 12.7 & 17.2 & 12.6 & 8.3 \\
\hline
\end{tabular}

According to the test results, further refinement scheme $\mathrm{B}$ and scheme D, color selection were dark brown and black, the shell materials are all engineering plastics, as shown in 
Figure 3 and 4 respectively for the plane effect is shown in Figure two phone scheme.
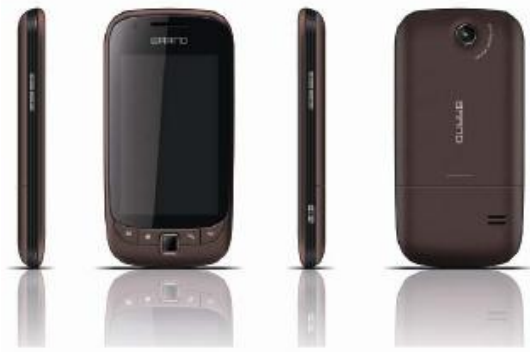

Fig.3 Rendering of scheme B
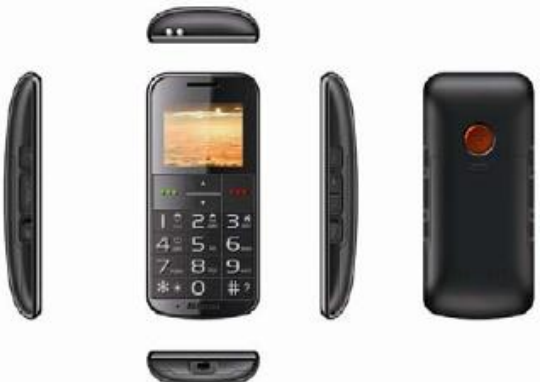

Fig.4 Rendering of scheme D

- Animation design, color swatch matching, mapping

- complete the appearance model and concept design prototype

- using 3D aided design to complete the design of specific work, make computer samples

- Users test

Results: to confirm the design scheme

5) Implementation

In order to verify the appearance of mobile phone product design and ergonomics size problem, through the production of 1:1 size prototype, and external identical material to verify the model, Figure 5 is the mobile phone model.

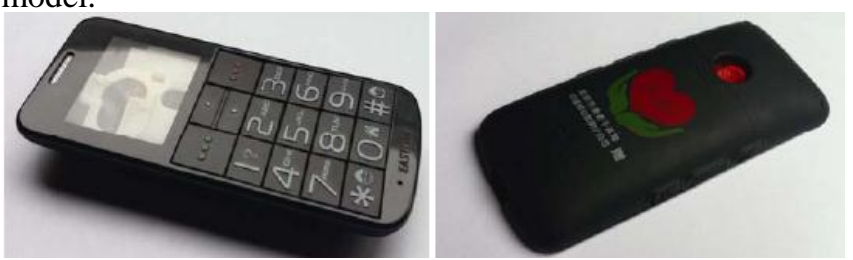

Fig.5 Mobile phone 1:1 model

$6)$ prototype test and repeated design

According to the product user test results, first review by the expert, choose the representative question to discuss, and then proceed to modify the products, will modify the good products in time for presentation to the user and then tested, and then review, modify, repeatedly until the product reaches the design goal of the design. Repeated design process is as shown in figure 6.

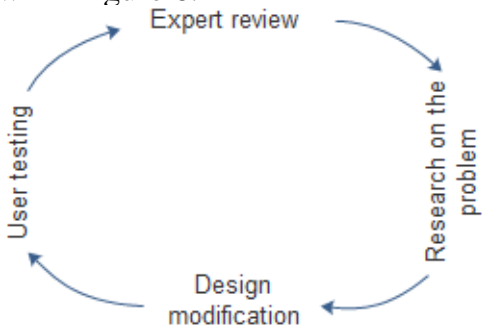

Fig.6 Repeated design process

7) To discuss and develop production plan.

- Submitted design final samples

- Determine the production specifications and technical parameter

Results: to production

\section{CONCLUSIONS}

The focus of the study is to develop the design of mobile phone products for the elderly, the core in design is "take the customer as the center", user is participate in various stages in the whole process of product design, targeted access to the elderly user demand information, designed for old people that they really needed products. The paper expounds the operation of usability engineering theory in the actual case, to test the feasibility of the application of usability engineering theory in the design of industrial product.

\section{REFERENCE}

[1] Li Xiunan. Sedimentation study of customer value- Taking mobile phone as Example [D]. master's degree paper of Zhejiang University, 2005

[2] Guo Ming. Maslow's "hierarchy of needs theory" analysis [J]. Journal of Shangqiu Normal University, 2007 (10).

[3] Tong Shizhong. The principle of modular design method and its application [M]. Chinese Standards Press of China, 2005 (5): 385

[4] Yi Xiao. From the man-machine interface to the user interface [J]. design and art, 2004

[5] Jiangshan, Liu Wei. Interface design of an aging society and products [J]. science Educ, 2006 (11): 174-176. 